\title{
Sensory Characteristics of Two Kinds of Alcoholic Beverages Produced with Spent Coffee Grounds Extract Based on Electronic Senses and HS-SPME-GC-MS Analyses
}

\author{
Lu Wang ${ }^{1,2}$, Xu Yang ${ }^{1}$, Zhuoting Li ${ }^{1}$, Xue Lin ${ }^{1,2, *} \mathbb{C}$, Xiaoping $\mathrm{Hu}^{1,2}$, Sixin Liu ${ }^{3}$ and Congfa $\mathrm{Li}^{1,2, *}$ \\ 1 College of Food Science and Engineering, Hainan University, Haikou 570228, China; \\ lwang@hainanu.edu.cn (L.W.); xu.yang@cansinotech.com (X.Y.); huanyuanjiang@hainanu.edu.cn (Z.L.); \\ huxiaoping03@hainanu.edu.cn (X.H.) \\ 2 Key Laboratory of Food Nutrition and Functional Food of Hainan Province, Haikou 570228, China \\ 3 College of Sciences, Hainan University, Haikou 570228, China; 990495@hainanu.edu.cn \\ * Correspondence: 993048@hainanu.edu.cn (X.L.); congfa@hainanu.edu.cn (C.L.); \\ Tel./Fax: +86-898-66278326 (X.L. \& C.L.)
}

\section{check for}

updates

Citation: Wang, L.; Yang, X.; Li, Z.; Lin, X.; Hu, X.; Liu, S.; Li, C. Sensory Characteristics of Two Kinds of Alcoholic Beverages Produced with Spent Coffee Grounds Extract Based on Electronic Senses and HS-SPME-GC-MS Analyses. Fermentation 2021, 7, 254. https:// doi.org/10.3390/fermentation7040254

Academic Editors: Bin Tian and Jicheng Zhan

Received: 10 September 2021

Accepted: 28 October 2021

Published: 1 November 202

Publisher's Note: MDPI stays neutral with regard to jurisdictional claims in published maps and institutional affiliations.

Copyright: (c) 2021 by the authors. Licensee MDPI, Basel, Switzerland. This article is an open access article distributed under the terms and conditions of the Creative Commons Attribution (CC BY) license (https:// creativecommons.org/licenses/by/ $4.0 /)$.

\begin{abstract}
In this work, the hydrothermal extract of spent coffee grounds (SCG) was used to make alcoholic beverages with commercial S. cerevisiae strain D254. The sensory characteristics of the SCG alcoholic beverages were analyzed using sensory description, electronic nose, electronic tongue, and gas chromatography-mass spectrometry (GC-MS). The results suggested that the supplement of $0.20 \%$ $\left(\mathrm{NH}_{4}\right)_{2} \mathrm{HPO}_{4}$ was effective at improving growth and alcohol fermentation of Saccharomyces cerevisiae D254 in SCG extract. SCG fermented beverages (SFB) and SCG distilled spirits (SDS) produced at the optimized fermentation conditions had appropriate physicochemical properties and different sensory characteristics. Fermentation aromas, especially esters, were produced in SFB, increasing the complexity of aroma and lowing the irritating aroma. The combination of original and fermentation components might balance the outstanding sourness, astringency, and saltiness tastes of SFB. The fermentation aroma was partially lost and the sourness, bitterness, astringency, and saltiness tastes were relieved in distillation, leading to the relatively more prominent aroma typicality of coffee and a soft taste. These findings lay a foundation for producing new high-quality coffee-flavored alcoholic beverages or flavoring liquors.
\end{abstract}

Keywords: spend coffee grounds; fermentation; sensory property; volatile profile

\section{Introduction}

Coffee is one of the most popular beverages worldwide because of its unique flavor and positive effects on health [1]. It has been consumed for over 1000 years and the demand of coffee production is growing steadily [2]. Nevertheless, spent coffee grounds (SCG) are inevitably produced during the processing of instant coffee $[3,4]$. Producing $1 \mathrm{~kg}$ of instant coffee could yield $0.9 \mathrm{~kg}$ of by-product SCG simultaneously [4,5]. As the main coffee industry residue, the vast majority of SCG are unconsumed and disposed of into the environment, leading to serious environmental pollution [6]. The reuse of SCG is thus of huge importance from environmental and economic viewpoints.

Resource utilization of SCG is currently of increasing concern. To improve the added value of SCG, some scholars and enterprises try to use SCG in many ways, such as being processed to feed and fertilizer [7], extraction of oil [8], obtaining polyphenols and dietary fiber from SCG [9,10], or using them for fuel production and alcoholic beverages making [11-14]. In South America and Vietnam, people have a tradition of drinking alcoholic beverages of coffee. Coffee-flavored alcoholic beverages, which can be drunk directly or used to prepare cocktails, are generally produced by the mixture of distilled liquor (such as edible alcohols, brandy, rum, and rice wines), coffee, sugar, cream, and other ingredients on the market. This method is relatively convenient for preparing coffee-flavored alcoholic beverages. 
However, the fusion of aromas is not satisfactory enough in this type of alcoholic beverage and the flavor is not typical or full.

SCG are rich in high value molecules and organic compounds and might retain the typical flavor and taste of coffee [14,15], making it a source of brewing potential for new coffee-flavored alcoholic beverages or flavoring liquors. Liu et al. [16-18] develops SCG fermented beverages (SFB) using different inoculation strategies and analyzes the changes of strains growth and chemical compositions in fermentation. Sampaio et al. [11] produces SCG distilled spirits (SDS) using SCG extract and analyzes the sensory profile. Machado et al. [14] produces SFB and SDS using SCG extract and also conducts a sensory evaluation. Sensory attributes are one of the most important factors affecting alcoholic beverages' quality and consumer preference. At present, electronic sensing technologies are widely used in the flavor evaluation of fermented food. The amount of research reporting on the combination of electronic nose/electronic tongue, gas chromatographymass spectrometry (GC-MS), and sensory description to evaluate the sensory characteristics of food is increasing [19-21]. However, the sensory evaluation of SCG alcoholic beverages by integrating the above-mentioned methods has not been reported.

In this study, to further characterize the fermentation potential of SCG extract and enrich the understanding of the sensory quality of the two kinds of SCG extract products SFB and SDS, the sensory characteristics of SFB and SDS produced at the optimized fermentation conditions were evaluated using sensory description, electronic nose, electronic tongue, and headspace solid-phase microextraction (HS-SPME) combined with GC-MS.

\section{Materials and Methods}

\subsection{Raw Material and Yeast Strain}

SCG used in this study were the by-products created during the processing of Arabica green coffee beans to instant coffee, in which countercurrent continuous extraction was conducted, and were provided by Hainan Lisun investment holding Co., Ltd. (Haikou, China). SCG were dried at $68{ }^{\circ} \mathrm{C}$ to a moisture content of about $10 \%$ and refrigerated for later use. The commercial S. cerevisiae strain D254 was purchased from LALVIN (Fredericia, Denmark).

\subsection{Fermentation Process}

The fermentation process of SCG alcoholic beverages is shown in Figure S1. SCG and distilled water were mixed in a proportion of $1: 5(\mathrm{~g} / \mathrm{mL})$ and heated at $95^{\circ} \mathrm{C}$ for $45 \mathrm{~min}$. After cooling and filtering with 500 mesh filter cloth, the SCG extract was obtained (2.5 $5^{\circ}$ Brix, pH 5.26). According to Sampaio et al. [11] and Machado et al. [14], $200 \mathrm{mg} / \mathrm{L}$ sodium metabisulfite was used to avoid bacterial contamination.

For the analysis of fermentation blocked in the SCG extract, the following media were used: (1) SCG extracts were mixed with $20 \%$ sucrose and $\mathrm{pH}$ was adjusted to 4.0 by $\mathrm{HCl}$, obtaining the SCE medium, (2) the modified RAE medium contained $20 \%$ sucrose, $1 \%$ yeast extract, $1 \%$ peptone, $0.3381 \% \mathrm{Na}_{2} \mathrm{HPO}_{4} \cdot 12 \mathrm{H}_{2} \mathrm{O}$, and $0.151 \%$ citric acid and $\mathrm{pH}$ was adjusted to 4.0 by HCl, (3) water in the RAE medium was replaced by SCG extract and other compositions remained unchanged, obtaining the RS medium, (4) $\mathrm{Na}_{2} \mathrm{HPO}_{4} \cdot 12 \mathrm{H}_{2} \mathrm{O}$ was removed from the RS medium to obtain the RS-P medium, and (5) yeast extract and peptone were removed from the RS medium to obtain the RS-N medium.

To ensure the smooth fermentation of SCG alcoholic beverages, the optimization of nutrition was conducted at the following condition: SCG extract was mixed with $20 \%$ sucrose and $\mathrm{pH}$ was adjusted to 4.0 by citric acid (equivalent to $2.54 \pm 0.09 \mathrm{~g} / \mathrm{L}$ citric acid in SCG extract) according to Sharma et al. [22] and Hlaing and Joshy [23]. Natively, $2.45 \pm 0.03 \mathrm{~g} / \mathrm{L}$ of citric acid exists in the SCG extract used in this work. Yu et al. [24] reports that citric acid has no obvious effects on the cell count, mortality rate, and alcohol fermentation ability of Saccharomyces cerevisiae at a concentration below $19.0 \mathrm{~g} / \mathrm{L}$ (equivalent to $\mathrm{pH}$ 2.51) in apple wine making. Citric acid has no obvious effects on the volume of S. cerevisiae cells at a concentration below $5.4 \mathrm{~g} / \mathrm{L}$ (equivalent to $\mathrm{pH} 2.97$ ) in the tested conditions. However, citric acid remarkably affects the growth and alcohol fermentation 
of S. cerevisiae at high concentrations $(32.8 \mathrm{~g} / \mathrm{L}, 47.1 \mathrm{~g} / \mathrm{L}$, and $61.5 \mathrm{~g} / \mathrm{L}$, equivalent to $\mathrm{pH}$ 2.31, 2.17, and 2.03, respectively). Wang et al. [25] finds similar results using the basic medium YEPD ( $20 \mathrm{~g} / \mathrm{L}$ glucose, $20 \mathrm{~g} / \mathrm{L}$ peptone, and $10 \mathrm{~g} / \mathrm{L}$ yeast extract). Nitrogen sources were supplemented by $\mathrm{NH}_{4} \mathrm{Cl},\left(\mathrm{NH}_{4}\right)_{2} \mathrm{SO}_{4}$, or $\left(\mathrm{NH}_{4}\right)_{2} \mathrm{HPO}_{4}$ at a concentration of $0.05 \%, 0.10 \%, 0.20 \%, 0.40 \%, 0.80 \%, 1.60 \%$, and $2.00 \%$, successively. Then, $4 \%$ activated (equivalent to about $5.0 \mathrm{Log} \mathrm{CFU} / \mathrm{mL}$ cells, hydration in $5 \%$ of glucose solution at $37^{\circ} \mathrm{C}$ for $30 \mathrm{~min}$ ) commercial yeast strains were added to the media, and the main fermentation was conducted at $25^{\circ} \mathrm{C}$ for 9 days.

After the main fermentation (in which time alcohol fermentation basically finished and the difference of $\mathrm{CO}_{2}$ production in two consecutive days was below $0.5 \mathrm{~g} / \mathrm{L}$ ) at the optimal condition, the post fermentation (during which time a small amount of residual sugar was used and SCG alcoholic beverages tended to be biologically stable) was conducted at $15^{\circ} \mathrm{C}$ for 30 days.

SCG distilled spirits were obtained using the traditional secondary distillation method. The fresh SCG fermented beverages were distilled in a pre-concentration step to obtain the primary distillate product at an ethanol content of about $25 \%$, and the head part $(1.5 \%$ of the fresh sample) was removed. Then, the primary distillate product was distilled below $85{ }^{\circ} \mathrm{C}$ in the second distillation. $1.5 \%$ of the distillate was removed. The heart distillate was collected at an ethanol content above $40 \%$ and the ethanol content of SCG distilled spirits was adjusted to $50 \%$ using ultrapure water. The fermentations were conducted three times.

\subsection{Analysis of Yeast Growth}

The cell density was measured at $30^{\circ} \mathrm{C}$ using a UV spectrophotometer (T6, Persee, Beijing, China). The yeast cells were centrifuged at $1500 \times g$ for $15 \mathrm{~min}$ and washed two times with $4{ }^{\circ} \mathrm{C}$ sterile water. Then, yeast cells were dried at $105^{\circ} \mathrm{C}$ to constant weight. The final biomass yield was determined by the gram of dry cells per liter fermentation broth.

\subsection{Analysis of $\mathrm{CO}_{2}$ Production}

$\mathrm{CO}_{2}$ weight loss was measured using an analytical balance (EL602, Mettler Toledo, Shanghai, China). The $\mathrm{CO}_{2}$ weight loss rate was expressed as the gram of $\mathrm{CO}_{2}$ weight loss production per liter of fermentation broth per fermentation time.

\subsection{Analysis of Physicochemical Properties}

Residual sugar was determined by titration with methylene blue indicator. An appropriate glucose standard solution $(2.5 \mathrm{~g} / \mathrm{L})$ mixed with $5 \mathrm{~mL}$ Fehling solutionI, $5 \mathrm{~mL}$ Fehling solutionII, and $50 \mathrm{~mL}$ distilled water. After boiling for $2 \mathrm{~min}$, two drops of methylene blue indicator were added and the glucose standard solution was used to titrate. The total volume of glucose standard solution consumed $(\mathrm{V})$ was recorded when the reaction solution was colorless. The volume of glucose standard solution consumed $\left(\mathrm{V}^{\prime}\right)$ was recorded when the appropriate samples replaced the glucose standard solution in the first step of above-mentioned method. The gram of glucose that was equivalent to that in $5 \mathrm{~mL}$ Fehling solutionI and II $(\mathrm{F})=$ grams of anhydrous glucose used $\times \mathrm{V} / 1000$. The residual sugar of sample $=\mathrm{F} \times 1000 /$ (volume of sample used /volume of sample used after dilution) $\times \mathrm{V}^{\prime}$. The results were expressed as glucose. Total acidity was determined by direct titration of organic acids in samples with $0.05 \mathrm{~mol} / \mathrm{L} \mathrm{NaOH}$ solution. A pH of 8.2 was used as the end point of potentiometric titration. The content of total acid of sample $=0.05 \times 75 \times$ (volume of $\mathrm{NaOH}$ solution for titrating the sample-volume of $\mathrm{NaOH}$ solution for titrating the control group)/volume of sample used. The results were expressed as tartaric acid. Ethanol content was obtained by distillation combined with a portable densimeter (DA-130N, KEM, Tokyo, Japan). $\mathrm{pH}$ was determined by using a $\mathrm{pH}$ meter (SevenEasy S20, METTLER TOLEDO, Zurich, Switzerland). Total esters were determined by titration with $0.1 \mathrm{~mol} / \mathrm{L}$ sulfuric acid solution. An appropriate $0.1 \mathrm{~mol} / \mathrm{L} \mathrm{NaOH}$ solution was used to neutralize the free acid in $50 \mathrm{~mL}$ samples. Two drops of phenolphthalein were used as the reaction indicator. After adding $25 \mathrm{~mL}$ of $0.1 \mathrm{~mol} / \mathrm{L} \mathrm{NaOH}$ solution, esters 
saponification was conducted by heating reflux on a boiling water bath for $30 \mathrm{~min}$. Then, $0.1 \mathrm{~mol} / \mathrm{L}$ sulfuric acid solution was used to titrate the sample. The content of total ester of sample $=0.01 \times 88 \times($ volume of sulfuric acid solution for titrating the sample-volume of sulfuric acid solution for titrating the control group)/volume of sample used. The results were expressed as ethyl acetate.

\subsection{Analysis of Volatile Profile}

HS-SPME-GC-MS was used to extract and analyse the volatiles. The SPME fiber (75 $\mu \mathrm{m}$ CAR/PDMS, Supelco, PA, USA) was pretreated in the GC injector at $250{ }^{\circ} \mathrm{C}$ for $30 \mathrm{~min}$ with $1.0 \mathrm{~mL} / \mathrm{min}$ flow rate of carrier gas, and $5 \mathrm{~g}$ samples were sealed in a $20 \mathrm{~mL}$ headspace vial and stirred at $400 \mathrm{r} / \mathrm{min}$. After equilibrating in a $50{ }^{\circ} \mathrm{C}$ water bath for $10 \mathrm{~min}$, the aged SPME fiber was suspended $1.6 \mathrm{~cm}$ above the sample for $40 \mathrm{~min}$ and desorbed in the GC injector at $250{ }^{\circ} \mathrm{C}$ for $5 \mathrm{~min}$.

Compound analysis was performed using an Agilent 7890A GC (Agilent, Santa Clara, CA, USA) coupled with an Agilent 5975C mass spectrometer system equipped with a DB-WAX capillary column $(60 \mathrm{~m} \times 0.25 \mathrm{~mm} \times 0.25 \mu \mathrm{m}$, Agilent, Santa Clara, CA, USA). Helium (purity $99.999 \%$ ) was used as the carrier gas at $2.0 \mathrm{~mL} / \mathrm{min}$. The oven was initially held at $40{ }^{\circ} \mathrm{C}$ for $6 \mathrm{~min}$, subsequently raised to $100{ }^{\circ} \mathrm{C}$ at a rate of $3{ }^{\circ} \mathrm{C} / \mathrm{min}$, and finally raised to $230{ }^{\circ} \mathrm{C}$ at a rate of $5{ }^{\circ} \mathrm{C} / \mathrm{min}$ for $10 \mathrm{~min}$. The electron ionization energy of the mass-selective detector was $70 \mathrm{eV}$. The chromatogram was recorded by monitoring the total ion currents in the $\mathrm{m} / \mathrm{z}$ range of 30 to 450 atomic mass units.

The volatile compounds were identified by comparing retention indices and retention times with those obtained for authentic standards, or those of literature data, or with mass spectra in the NIST/WILEY Database. The relative quantification of volatile compounds was performed by peak area method, and $20 \mu \mathrm{L}$ 2-Methoxy-d3-phenol-3,4,5,6-d4 $(410 \mathrm{mg} / \mathrm{L})$ was used as an internal standard.

\subsection{Electronic Nose Analysis}

The Germany Airsense PEN 3 portable electronic nose system (Schwerin, MecklenburgVorpommern) was used to estimate the aroma profile of SCG alcoholic beverages. The performance of ten metal oxide semiconductor sensors is listed in Table S1.

A $10 \mathrm{~mL}$ sample (diluted to $10 \%$ vol ethanol with ultrapure water) was sealed in a sample vial for $60 \mathrm{~min}$ for data collection. The headspace sampling method was used for electronic nose detection. Detection conditions were set as follows: the sensor cleaning time was $170 \mathrm{~s}$, the auto-zero time was $10 \mathrm{~s}$, the sample preparation time was $5 \mathrm{~s}$, the injection rate of gas and carrier gas speed were $400 \mathrm{~mL} / \mathrm{min}$, and the detection time was 120 s. Samples were analyzed using WinMuster statistical analysis software self-contained with PEN 3 and the sensor response values at $98 \mathrm{~s}$ were used to establish the radar chart.

\subsection{Electronic Tongue Analysis}

Electronic tongue analysis was performed on an SA402B system (Insent, Kanagawa, Japan) equipped with seven sensors and reference electrodes, which could analyze bitterness, sourness, saltiness, sweetness, astringency, and bitter anion tastes. The composition of electrode and standard solutions is shown in Table S2. The ethanol concentration of samples was diluted to $10 \%$ vol with ultrapure water and the supernatants were used for analysis.

\subsection{Sensory Evaluation}

SFB and SDS were evaluated by a well-trained panel of 11 members (6 men and 5 women, ranging from 20 to 55 years old). Then, $20 \mathrm{~mL}$ of samples was presented to the panelists at $21 \pm 1{ }^{\circ} \mathrm{C}$. The sensory scoring criteria and rules were set based on those of dry grape wine, taking into account the sensory characteristics of coffee. The specific sensory scoring rules of SCG fermented beverages were shown in Table S3. 


\subsection{Statistical Data Analysis}

Results were shown as averages of at least three independent experiments \pm SD. Statistically significant differences $(p<0.05)$ were determined using one-way ANOVA and Tukey's honestly significant difference (HSD) tests.

\section{Results and Discussion}

\subsection{Analysis of Fermentation Blocked in SCG Extract}

In our previous study, the fermentation capacity of four yeast strains, S. cerevisiae D254, S. bayanus BV818, S. bayanus DV10, and S. bayanus EC1118, commonly used in fruit wine industry, was evaluated in SCG extract [26]. Surprisingly, the four yeast strains exhibited inferior capacities of producing $\mathrm{CO}_{2}$ and ethanol in SCE (Table S4, [26]). We speculated that this problem may be related to insufficient nitrogen and phosphorus sources and the existence of a toxic component, such as coffee polyphenols, in the SCG extract. In previous studies, Liu et al. [16-18] comprehensively analyzed the chemical composition of SCG hydrolysates before and after the microbial transformation, and found the insufficient assimilable nitrogen of unfermented SCG hydrolysates. As shown in Table S5, regarding the chemical parameters of unfermented SCG extract used in this work, a similar phenomenon was observed, revealing the necessity of supplementing with a nitrogen source in SCG extract fermentation.

In this study, firstly, the reasons for the weak fermentation of yeast strains in the SCG substrate were analyzed using the "medium components addition/subtraction" method. The strain S. cerevisiae D254, which was relatively more suitable for SCG extract fermentation in terms of ethanol content and sensory characteristics, was used in this work. As shown in Figure 1a, compared with that in SCE, the growth of S. cerevisiae D254 improved obviously in RAE, RS, and RS-P media. The biomass yield of S. cerevisiae D254 achieved or even exceeded $3.0 \mathrm{~g} / \mathrm{L}$ in RAE, RS, and RS-P media, whereas only $1.4 \mathrm{~g} / \mathrm{L}$ biomass yield was observed in SCE (Figure 1b). Simultaneously, the residual sugar and ethanol content in RAE, RS, and RS-P were close to the theoretical values (Figure 1c). However, similar slow growth and fermentation to those in SCE were displayed in the RS-N medium.

These results were corresponding to the analysis of chemical parameters of SCG extract and also indicated that an insufficient nitrogen source was the main factor of weak fermentation in SCG substrate, whereas SCG extract and phosphorus source were not the key limiting factors for yeast strains in SCG substrate.

Generally speaking, the lack of assimilatable nitrogen source is a common cause of slow and stagnant fermentation in yeast [27]. The level of nitrogen source could influence the genes expression of yeasts [28]. Yeast cells behave similar as when under carbon starvation at a low concentration of nitrogen, inhibiting their growth and metabolism [29]. In this work, the growth of S. cerevisiae D254 was slow with the lack of nitrogen sources; no rapid growth period and few biomass accumulations were observed under the same conditions. This result was consistent with that of Hernandez-Orte et al. [30], which showed that nitrogen source directly affected the biomass of yeast in the rapid growth period at the initial stage of fermentation. Insufficient biomass could lead to the slow fermentation and prolong the fermentation time. 

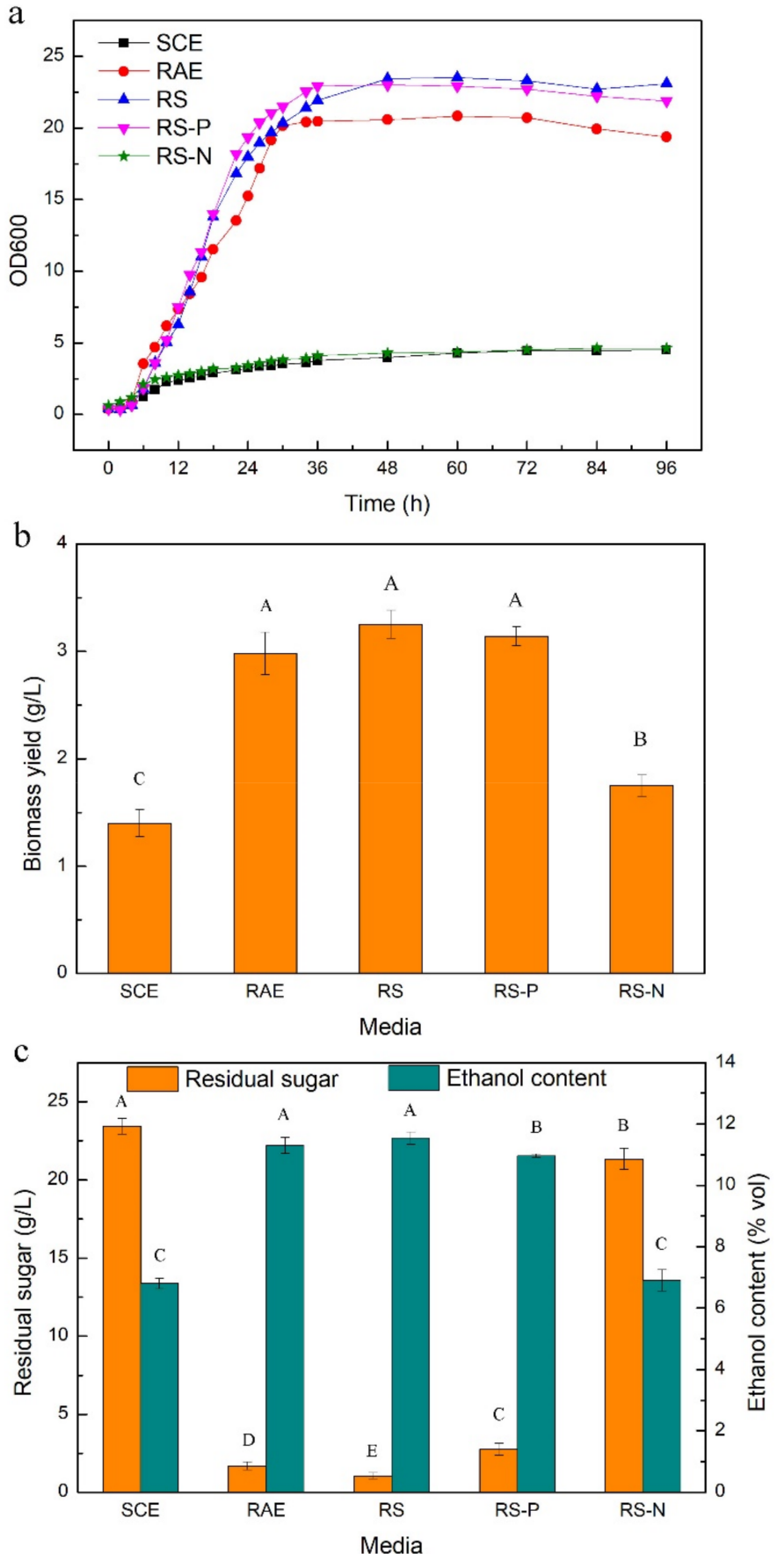

Figure 1. The growth and fermentation properties of S. cerevisiae D254 in different substrates. (a) The growth of D254 was monitored using OD600 and (b) the biomass yield was calculated using cell dry weight per liter medium. (c) The residual sugar of fermentation end point was tested. SCE medium: Spent coffee ground (SCG) extracts mixed with $20 \%$ sucrose and $\mathrm{pH}$ was adjusted to 4.0 by HCl. RAE medium: $20 \%$ sucrose, $1 \%$ yeast extract, $1 \%$ peptone, $0.3381 \% \mathrm{Na}_{2} \mathrm{HPO}_{4} \cdot 12 \mathrm{H}_{2} \mathrm{O}$, and $0.151 \%$ citric acid mixed and $\mathrm{pH}$ was adjusted to 4.0 by $\mathrm{HCl}$. RS medium: water in the RAE medium was replaced by SCG extract and other compositions remained unchanged. RS-P medium: $\mathrm{Na}_{2} \mathrm{HPO}_{4} \cdot 12 \mathrm{H}_{2} \mathrm{O}$ was removed from the RS medium. RS-N medium: yeast extract and peptone were removed from the RS medium. Values with different capital letters in the columns of the same color are significantly different $(p<0.05)$. 


\subsection{Optimization of Nitrogen Source for SFB}

Considering the high quality, high efficiency, low price, and easy availability of inorganic ammonium salts, different concentrations of $\mathrm{NH}_{4} \mathrm{Cl},\left(\mathrm{NH}_{4}\right)_{2} \mathrm{SO}_{4}$, and $\left(\mathrm{NH}_{4}\right)_{2} \mathrm{HPO}_{4}$ were used to try to improve alcohol fermentation [26]. As shown in Figure 2a, the addition of the three nitrogen sources performed different effects on the metabolism of $S$. cerevisiae D254. Overall, the growth and fermentation capacities enhanced first and then decreased with the increasing concentration of nitrogen sources. The highest biomass yield and ethanol content and the lowest residual sugar were observed at the addition of $0.20 \%$ of each nitrogen source, and the biomass yield and ethanol content in the addition of $\left(\mathrm{NH}_{4}\right)_{2} \mathrm{HPO}_{4}$ were higher than those seen with the addition of $\mathrm{NH}_{4} \mathrm{Cl}$ and $\left(\mathrm{NH}_{4}\right)_{2} \mathrm{SO}_{4}$ at the same concentration (Figure S2, [26]).
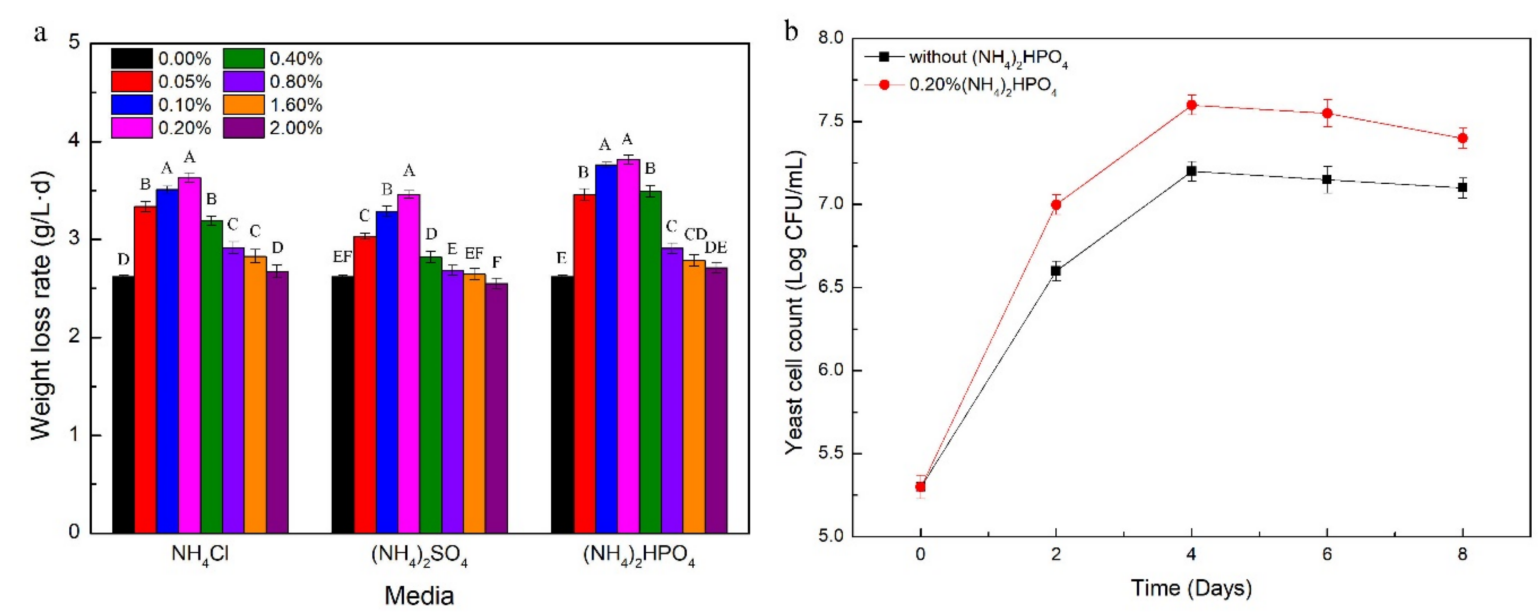

Figure 2. Effects of exogenous nitrogen sources on (a) $\mathrm{CO}_{2}$ weight loss rate of S. cerevisiae D254 and (b) growth of S. cerevisiae D254 in SCG substrate. The YEPD agar plate was used for the viable count of the yeast cells. Values with different capital letters in the columns of the same color are significantly different $(p<0.05)$.

These results reflected that appropriate addition of nitrogen source was promising and essential to the growth and alcohol fermentation of S. cerevisiae in SCG extract. The addition of $0.20 \%\left(\mathrm{NH}_{4}\right)_{2} \mathrm{HPO}_{4}$ could be used to improve the growth of S. cerevisiae D254 (Figure $2 \mathrm{~b}$ ) and solve the slow fermentation in SCG extract.

The addition of $0.20 \% \mathrm{NH}_{4} \mathrm{Cl} /\left(\mathrm{NH}_{4}\right)_{2} \mathrm{SO}_{4} /\left(\mathrm{NH}_{4}\right)_{2} \mathrm{HPO}_{4}$ was beneficial for cell growth and $\mathrm{CO}_{2}$ production. The decreased biomass yields at the nitrogen sources' levels above $0.20 \%$ might be caused by the negative effect of excess $\mathrm{NH}^{4+}$ on the utilization of amino acid in an amino acid starvation condition [31]. The low utilization of sugar under the same conditions might be attributed to the slow growth of yeast cells and the negative effect of excess nitrogen sources on the expression of genes related to the transport of ammonium salts/amino acids, such as GAP1 and MEP2 [28]. In addition, excessive nitrogen sources may form carcinogens urethane, biogenic amine, and nitrosamine [32,33], which could negatively affect the quality and safety of wines. $\left(\mathrm{NH}_{4}\right)_{2} \mathrm{HPO}_{4}$ could not only complement the nitrogen source but also provide phosphate ions, further improving the growth and metabolism of yeast cells.

Based on this result, other factors including the ratio of SCG-liquid, inoculation concentration, sugar degree, $\mathrm{pH}$, and fermentation temperature were optimized by singlefactor test (Figure S3). Using the content of residual sugar, total acidity, and ethanol and sensory score as evaluation indexes, the optimal main fermentation condition was set as follows: SCG-liquid ratio was 1:4; $0.2 \%\left(\mathrm{NH}_{4}\right)_{2} \mathrm{HPO}_{4}$ was added; initial sugar level was $24 \%$ sucrose; $\mathrm{pH}$ was adjusted to 4.3 by citric acid (equivalent to $2.51 \pm 0.02 \mathrm{~g} / \mathrm{L}$ citric acid in SCG extract, and the content of citric acid kept at $2.51 \pm 0.10 \mathrm{~g} / \mathrm{L}$ when the fermentation finished); $6 \%$ activated S. cerevisiae strain D254 (equivalent to about $5.3 \mathrm{Log}$ CFU $/ \mathrm{mL}$ cells) was inoculated; and the main fermentation was conducted at $23{ }^{\circ} \mathrm{C}$ for 8 days. 


\subsection{Physicochemical and Sensory Characteristics of SCG Alcoholic Beverages}

The contents of residual sugar, total acidity, ethanol, and total esters of SFB and SDS were analyzed at the optimal main fermentation condition. Furthermore, the sensory attributes including colour and lustre, aroma, and taste of SFB and SDS were described. As shown in Table 1, SFB and SDS exhibited suitable content of ethanol. The total acidity of SFB was $9.07 \mathrm{~g} / \mathrm{L}$, but that for SDS was only $0.37 \mathrm{~g} / \mathrm{L}$. The content of total esters of SDS decreased from $730.42 \mathrm{mg} / \mathrm{L}$ of SFB to $426.93 \mathrm{mg} / \mathrm{L}$. For the sensory attributes, compared with SFB, SDS possessed a more typical coffee aroma without fruity aroma, but lacked the multi-level, typical taste of coffee.

Table 1. General physicochemical properties of SFB and SDS.

\begin{tabular}{ccc}
\hline Indexes & SFB & SDS \\
\hline Residual sugar (g/L) & $6.27 \pm 0.51$ & \multicolumn{1}{c}{$50.5 \pm 0.2$} \\
Ethanol (\% vol) & $12.5 \pm 0.1$ & $0.37 \pm 0.02$ \\
Total acidity (g/L) & $9.07 \pm 0.43$ & $426.93 \pm 44.28$ \\
Total esters (mg/L) & $730.42 \pm 46.65$ & Light amber, clear, and transparent \\
Colour and lustre & Yellowish-brown, clear, and transparent & A typical and rich coffee aroma with a \\
Aroma & Typical coffee, sweet fruity, and good aroma & wine aromas \\
Taste & Full-bodied wine with a harmonious and & Mellow, soft, and elegant wine \\
\hline
\end{tabular}

/: not tested. Spent coffee grounds: namely SCG. SCG fermented beverages: namely SFB. SCG distilled spirits: namely SDS.

These results suggested that SFB and SDS had different sensory styles with distinguished physicochemical characteristics. Acids play a role in presenting flavor in wines [34]. The total acidity of SFB was higher than that of most fruit wines, in which the acidity content is commonly below $8 \mathrm{~g} / \mathrm{L}$. Meanwhile, the total acidity of most SFB samples possessing a high sensory score was higher than $8 \mathrm{~g} / \mathrm{L}$ (Figure S3). The high content of acidity could balance the bitter odor of coffee, contributing to a harmonious and palatable taste of SFB. The acids in SFB include dicaffeoylquinic acid, caffeic acid, quinic acid, citric acid, tartaric acid, and acetic acid [35-37]. As the main acids of coffee, the former three ones hardly evaporate in distillation, resulting in the low acidity of SDS. Enough acids could provide more precursors of esters. Esters are one of the most important volatile compositions that contribute to wine flavor [38]. The high content of total esters of SFB could bring about a fruity aroma. Esters were inevitably lost in distillation. The content of total esters of SDS was lower than that of Baijiu, but this level was similar to that of some distilled wines, such as brandy [39]. Therefore, SCG alcoholic beverages have development potential in terms of aroma, flavor, and style.

\subsection{Analysis of Electronic Nose and Electronic Tongue \\ 3.4.1. Analysis of Electronic Nose}

The electronic nose and electronic tongue were used to relatively objectively evaluate the aroma and taste characteristics of SCG alcoholic beverages, respectively. The response values of SCG extract and coffee liquid were similar in each sensor (Figure 3(a1)). Compared with SCG extract and coffee liquor, the response values of SFB and SDS in sensors S2, S6, S7, S8, and S9 were remarkably increased. PCA was used to study the similarities and differences of SCG extract, coffee, and SCG alcoholic beverages. The locations of SFB and SDS partially overlapped and separated from SCG extract and coffee, and the two groups overlapped in the second quadrant (Figure 3(a2)). 

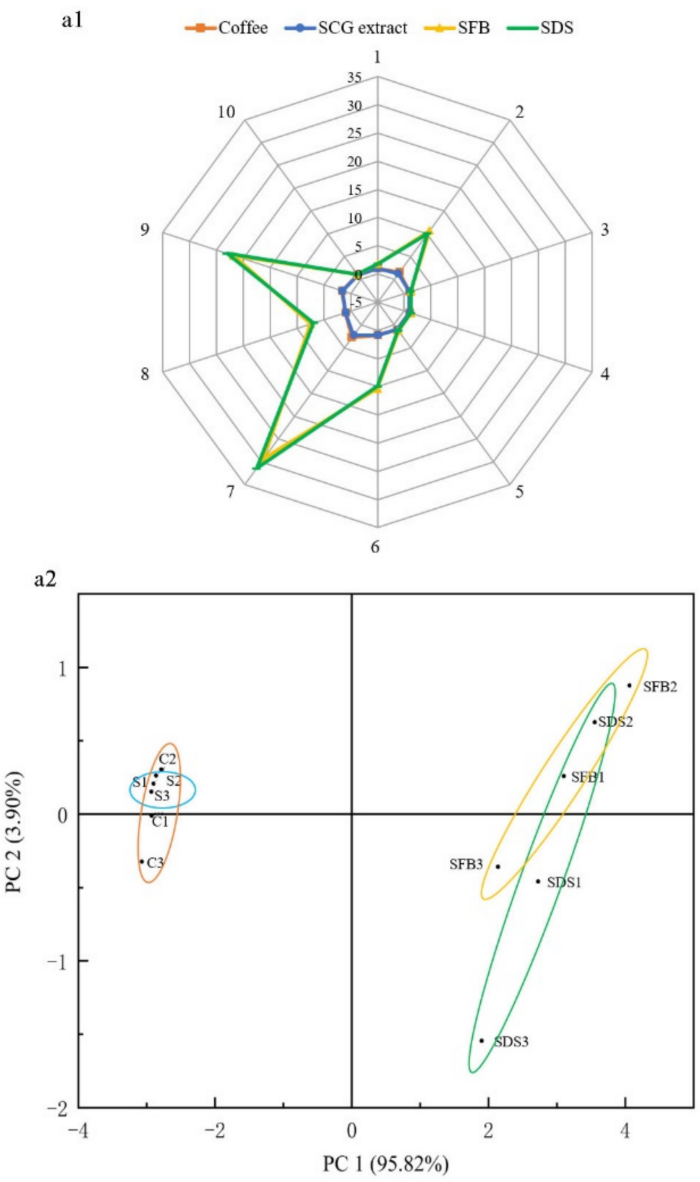
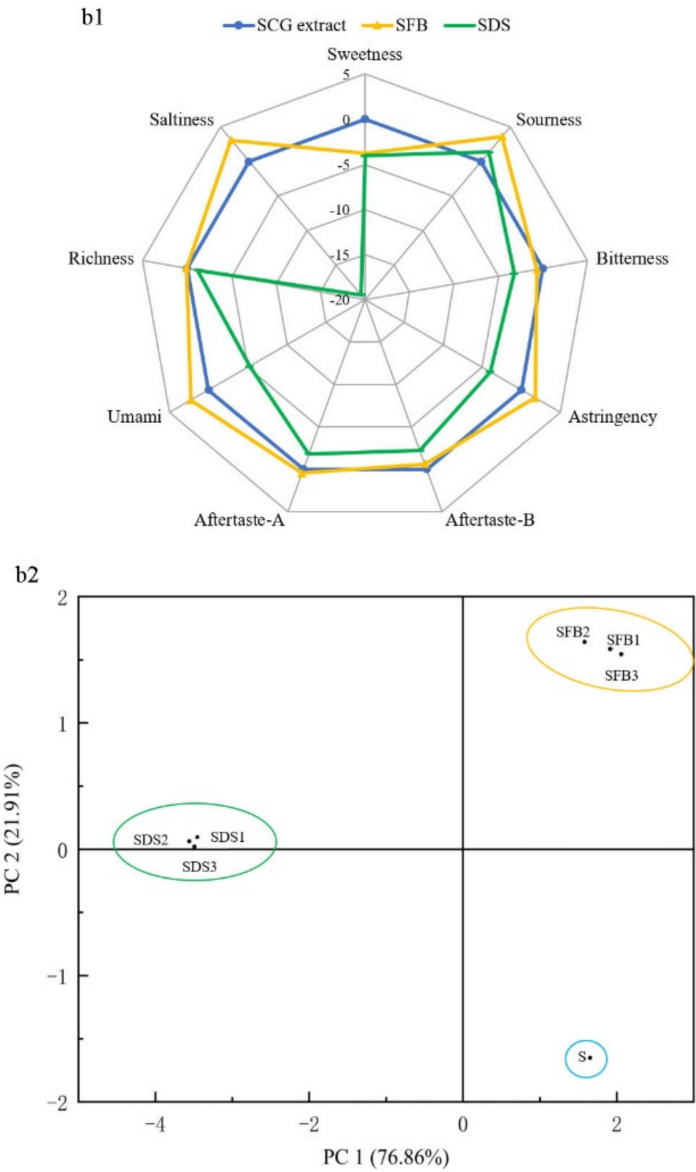

Figure 3. The analysis of the (a) electronic nose and (b) electronic tongue. (a1): Radar graph of samples' aroma, (b1): Radar graph of samples' taste. (a2,b2): PCA of samples. C: Coffee. S: SCG extract. SFB: SCG fermented beverages. SDS: SCG distilled spirits.

These results indicated that the SCG extract well retained the aroma of coffee and had the value for making coffee-flavored products. Fermentation and distillation affected the aroma profile of SCG extract and coffee. The difference between SCG alcoholic beverages and SCG extract/coffee on aromas was probably caused by the increase of nitrogen oxides, sulfides, alcohols, and other substances during fermentation.

\subsubsection{Analysis of Electronic Tongue}

Compared with SCG extract, SFB exhibited strong sourness, astringency, umami, and saltiness tastes and astringency aftertaste with thin sweetness and bitterness tastes and bitter aftertaste. A similar richness taste to SCG extract was observed in SFB. However, the response to eight taste attributes, excluding sourness, in SDS was lower than those in SCG extract (Figure 3(b1)). SCG extract, SFB, and SDS were located in three different quadrants in the PCA result (Figure 3(b2)).

Compared with SDS, SFB had a prominent coffee taste with strong sourness and astringency feeling. Nevertheless, typical coffee flavor did not represent high consumer acceptance. Some consumers had low acceptance of pure coffee flavor. The final taste characteristic of alcoholic beverages depended on the balance and coordination of all taste attributes.

Sourness, sweetness, bitterness, and saltiness tastes are four main senses of coffee [40]. The sour and astringent tastes of coffee are largely come from a variety of organic acids, such as citric acid, malic acid, tartaric acid, chlorogenic acid, and its degradation product dicaffeoylquinic acid, in the baking process $[35,40,41]$. The content of organic acids increased during fermentation, and the solubility of dicaffeoylquinic acid in ethanol was higher than that in water [42]. Therefore, sour and astringent substances increased in SFB 
and the corresponding taste senses enhanced. Sugars of coffee can give a sweet taste, and the caramel compounds produced in the baking process can give sweet and bitter tastes. With the decomposition of sugars in fermentation, the sweetness and bitterness tastes reduced, which in turn made the sourness and saltiness tastes more prominent. Combined with the results of taste evaluation in Table 1, the findings suggested that such changes of taste of coffee in fermentation were favor to the mutual inhibition and balance of sourness, sweetness, bitterness, and saltiness senses in this study. Distillation was a process that selectively extracted the volatile flavor components of fermentation wines. Many compositions with strong water solubility and weak fat solubility could not be brought out with the distillation of ethanol. The prominent sour and astringent tastes in SFB reduced in distillation with less sweetness and saltiness senses, which were suitable for consumer groups with low acceptance of pure coffee. This finding was corresponded to the results of Machado et al. [14], in which SDS exhibited a high global value in quantitative descriptive analysis.

\subsection{Volatile Profile of SCG Alcoholic Beverages}

A total of 77 volatile compounds were identified in this study, including 15 esters, 8 alcohols, 1 acid, 8 aldehydes, 3 ketones, 4 phenols, 9 pyrazines, 16 furans, 7 terpenes, 3 pyrroles, 1 lactone, and 2 other compounds (Table 2). The most abundant variety but the lowest content of total volatile compositions was observed in SCG extract (Figure 4). The lowest variety of volatile compositions was observed in SDS with the moderate total content (Figure 4). SFB displayed the highest content of total volatiles with the moderate variety (Figure 4). These results suggested that the types and content of volatiles of SCG extract changed in fermentation and distillation. Partial original aromas of SCG extract were lost and converted in alcohol fermentation with the formation of a large amount of fermentation aromas. Both original and fermentation aromas were partially lost in distillation. The types and contents of volatiles differed from those reported in Machado et al. [14] and Liu et al. [16]. This discrepancy could be caused by the difference of extraction and test methods.

More than 800 aromatic components of coffee have been detected in previous studies, of which pyrazines, furans, aldehydes, and sulphur compounds are the key ones and contribute the most to coffee aroma $[37,40]$. Pyrazines have high contents and low odor thresholds, mainly giving nutty and baking odors [43]. Furans commonly contribute to balsamic, wheat, and baking odors [44]. Aldehydes giving fatty, spicy, sweety, and bread odors could confer a richer, more elegant, and unique aroma to wines [45]. Most sulphur compounds contribute to a negative sulphur aroma. The types and contents of typical aroma of coffee could be changed by different treatment conditions, such as baking temperature, extraction temperature, and extraction method, such as that of the extraction of phenolic/flavonoid compounds using different methods [46,47]. Only one sulphur compound was detected in this work. This result was not consistent to the strong response to sulfides in the electronic nose analysis. The detection method needs to be further optimized in future study. The above-mentioned four kinds of aromatic components accounted for $34.0 \%, 11.9 \%$, and 32.2\% in SCG extract, SFB, and SDS, respectively. A similar proportion of four key aromatic groups to SCG extract in SDS might bring the outstanding typicality of coffee aroma in Table 1 and Figure $4 \mathrm{a} 1$, though the fewest types of volatiles were observed in SDS. The proportion of original aroma in SFB decreased with increased fermentation aroma, producing a complex and rich aroma and more flavor levels of SFB. 
Table 2. The concentration of volatile compounds identified in SCG extract, SFB, and SDS.

\begin{tabular}{|c|c|c|c|c|c|}
\hline \multirow{2}{*}{ Code } & \multirow{2}{*}{ Compounds } & \multirow{2}{*}{ Odor Description * } & \multicolumn{3}{|c|}{ Concentration $(\mu \mathrm{g} / \mathrm{L})$} \\
\hline & & & SCG Extract & SFB & SDS \\
\hline & Esters & & & & \\
\hline E1 & Ethyl acetate & Pineapple & $7105 \pm 30^{B}$ & $36690 \pm 64^{\mathrm{A}}$ & $5094 \pm 22^{C}$ \\
\hline E2 & Ethyl propionate & Fruit & $230 \pm 4^{\mathrm{B}}$ & $936 \pm 12^{\mathrm{A}}$ & $19 \pm 2^{\mathrm{C}}$ \\
\hline E3 & Ethyl 2-methylpropanoate & Sweet, rubber & - & - & $33 \pm 2$ \\
\hline E4 & 2-Methyl-1-propyl acetate & Fruit, apple, banana & - & $33 \pm 3$ & - \\
\hline E5 & Ethyl butanoate & Apple & - & $148 \pm 5$ & - \\
\hline E6 & Ethyl 2-methylbutanoate & Apple & - & - & $75 \pm 3$ \\
\hline E7 & Ethyl 3-methylbutanoate & Fruit & - & $4 \pm 0.2$ & - \\
\hline E8 & Isoamyl acetate & Banana & $46 \pm 2^{C}$ & $1346 \pm 12^{\mathrm{A}}$ & $342 \pm 5^{B}$ \\
\hline E9 & Ethyl hexanoate & Apple peel, fruit & $63 \pm 2^{C}$ & $651 \pm 7^{\mathrm{A}}$ & $152 \pm 4^{\mathrm{B}}$ \\
\hline E10 & Ethyl octanoate & Fruit, fat & $172 \pm 5^{\mathrm{C}}$ & $717 \pm 12^{\mathrm{B}}$ & $878 \pm 16^{\mathrm{A}}$ \\
\hline E11 & Ethyl nonanoate & & - & $55 \pm 3$ & $11 \pm 1$ \\
\hline E12 & Furfuryl acetate & & - & $2194 \pm 22$ & - \\
\hline $\mathrm{E} 13$ & Ethyl decanoate & Grape & $62 \pm 2^{B}$ & $257 \pm 4^{\mathrm{A}}$ & $265 \pm 4^{\mathrm{A}}$ \\
\hline E14 & Ethyl butyrate & Apple & $84 \pm 4$ & - & - \\
\hline E15 & $\begin{array}{l}\text { Phenethyl acetate } \\
\text { Alcohols }\end{array}$ & Rose, honey, tobacco & - & $149 \pm 2$ & - \\
\hline A1 & 2-Methyl-1-butanol & Wine, onion & $473 \pm 7^{\mathrm{C}}$ & $7421 \pm 22^{\mathrm{A}}$ & $3898 \pm 15^{\mathrm{B}}$ \\
\hline $\mathrm{A} 2$ & 3-Methyl-1-butanol & Whiskey, malt, burnt & $810 \pm 21^{C}$ & $11804 \pm 32^{\mathrm{B}}$ & $12565 \pm 43^{\mathrm{A}}$ \\
\hline A3 & Isobutanol & Wine, solvent, bitter & $78 \pm 2^{\mathrm{C}}$ & $1480 \pm 10^{\mathrm{A}}$ & $377 \pm 4^{\mathrm{B}}$ \\
\hline A4 & 2-Heptanol & Mushroom & $35 \pm 4$ & - & - \\
\hline A5 & 2,3-Butanediol & Fruit, onion & $616 \pm 11$ & - & - \\
\hline A6 & 2-Furylmethanol & Burnt & $854 \pm 22^{\mathrm{B}}$ & $1789 \pm 14^{\mathrm{A}}$ & - \\
\hline A7 & Benzyl alcohol & Sweet, flower & $88 \pm 4^{\mathrm{A}}$ & $29 \pm 1^{B}$ & - \\
\hline A8 & $\begin{array}{l}\text { 2-Phenylethyl alcohol } \\
\text { Acids }\end{array}$ & Honey, spice, rose, lilac & $435 \pm 9^{\mathrm{B}}$ & $10183 \pm 34^{\mathrm{A}}$ & - \\
\hline $\mathrm{AC} 1$ & $\begin{array}{l}\text { Acetic acid } \\
\text { Aldehydes }\end{array}$ & Sour & $62 \pm 4^{\mathrm{B}}$ & $1017 \pm 23^{\mathrm{A}}$ & $58 \pm 3^{\mathrm{B}}$ \\
\hline Al1 & Ethanal & Pungent, ether & - & $617 \pm 10^{\mathrm{B}}$ & $1792 \pm 14^{\mathrm{A}}$ \\
\hline $\mathrm{A} 12$ & Isovaleraldehyde & Malt & $25 \pm 2$ & - & - \\
\hline $\mathrm{Al} 3$ & Acetaldehyde diethyl acetal & & - & - & $6395 \pm 21$ \\
\hline Al4 & (Z)-4-heptenal & Biscuit, cream & $42 \pm 2$ & - & - \\
\hline Al5 & Octanal & Fat, soap, lemon, green & $34 \pm 2$ & - & - \\
\hline Al6 & Nonanal & Fat, citrus, green & $289 \pm 5$ & - & - \\
\hline Al7 & Furfural & Bread, almond, sweet & - & - & $1027 \pm 22$ \\
\hline $\mathrm{Al} 8$ & $\begin{array}{l}\text { Phenylacetaldehyde } \\
\text { Ketones }\end{array}$ & Hawthorne, honey, sweet & $44 \pm 3^{\mathrm{B}}$ & - & $1093 \pm 13^{\mathrm{A}}$ \\
\hline K1 & 2-Methylpentan-3-one & Mint & $29 \pm 2^{\mathrm{A}}$ & $21 \pm 2^{\mathrm{B}}$ & - \\
\hline K2 & 2,3,4-Trimethyl-cyclopent-2-enone & & $137 \pm 4$ & - & - \\
\hline K3 & $\begin{array}{l}\text { Cyclopentanone } \\
\text { Phenols }\end{array}$ & & - & - & $19 \pm 1$ \\
\hline P1 & Phenol & Phenol & $322 \pm 7^{\mathrm{A}}$ & $80 \pm 3^{B}$ & - \\
\hline P2 & 4-Ethyl-2-methoxyphenol & Spice, clove & $1835 \pm 20^{\mathrm{A}}$ & $1232 \pm 16^{\mathrm{B}}$ & $89 \pm 4^{C}$ \\
\hline P3 & 2-Ethylphenol & & $61 \pm 3$ & - & - \\
\hline $\mathrm{P} 4$ & $\begin{array}{l}\text { 4-Allyl-2-methoxyphenol } \\
\text { Pyrazines }\end{array}$ & Clove, honey & $249 \pm 6^{\mathrm{A}}$ & $239 \pm 6^{\mathrm{A}}$ & - \\
\hline Py1 & 2-Methypyrazine & Popcorn & $159 \pm 8^{C}$ & $1130 \pm 21^{\mathrm{A}}$ & $221 \pm 5^{\mathrm{B}}$ \\
\hline Py2 & 2,5-Dimethyl pyrazine & $\begin{array}{l}\text { Cocoa, roasted nut, roast } \\
\text { beef, medicine }\end{array}$ & $60 \pm 2^{\mathrm{B}}$ & $477 \pm 13^{\mathrm{A}}$ & - \\
\hline Py3 & 2-Eethyl pyrazine & Peanut butter, wood & $64 \pm 5^{\text {B }}$ & $192 \pm 4^{\mathrm{A}}$ & $24 \pm 2^{C}$ \\
\hline Рy4 & 2-Ethyl-6-methylpyrazine & & - & - & $12 \pm 1$ \\
\hline Py5 & 2-Ethyl-5-methyl pyrazine & Fruit, sweet & $1901 \pm 22^{\mathrm{A}}$ & $1117 \pm 12^{\mathrm{B}}$ & - \\
\hline Py6 & 2-Methyl-3-ethylpyrazine & Roast & $77 \pm 5^{\mathrm{B}}$ & $424 \pm 8^{\mathrm{A}}$ & - \\
\hline Py7 & 2-Ethyl-3,6-dimethylpyrazine & Potato, roast & $1761 \pm 15^{\mathrm{A}}$ & $1538 \pm 26^{\mathrm{B}}$ & - \\
\hline Py8 & 3,5-Diethyl-2-methylpyrazine & Baked & $340 \pm 9^{B}$ & $381 \pm 8^{\mathrm{A}}$ & - \\
\hline Py9 & $\begin{array}{l}\text { 2,3-Diethyl-5-methylpyrazine } \\
\text { Furans }\end{array}$ & Potato, meat, roast & $313 \pm 6^{\mathrm{A}}$ & $286 \pm 6^{B}$ & - \\
\hline $\mathrm{F} 1$ & 2-(2-Propenyl)furan & & - & - & $52 \pm 2$ \\
\hline F2 & Furfuryl ethyl ether & & - & $1518 \pm 16^{\mathrm{A}}$ & $408 \pm 7^{\mathrm{B}}$ \\
\hline F3 & 2,5-Dimethylfuran & & $20 \pm 1^{\mathrm{B}}$ & $11 \pm 2^{C}$ & $40 \pm 1^{\mathrm{A}}$ \\
\hline F4 & 2-(2-Pentenyl)furan & & - & - & $225 \pm 2$ \\
\hline F5 & 5-Methyl-2-acetylfuran & & $70 \pm 2$ & - & - \\
\hline F6 & 2-Vinylfuran & & $269 \pm 7^{\mathrm{A}}$ & $39 \pm 1^{\mathrm{B}}$ & $38 \pm 1^{\mathrm{B}}$ \\
\hline F7 & 5-Methyl-2-furanaldehyde & $\begin{array}{l}\text { Almond, caramel, burnt } \\
\text { sugar }\end{array}$ & - & - & $156 \pm 3$ \\
\hline F8 & 2-Methyl-Furan & & $36 \pm 2$ & - & - \\
\hline
\end{tabular}


Table 2. Cont.

\begin{tabular}{|c|c|c|c|c|c|}
\hline \multirow{2}{*}{ Code } & \multirow{2}{*}{ Compounds } & \multirow{2}{*}{ Odor Description * } & \multicolumn{3}{|c|}{ Concentration $(\mu \mathrm{g} / \mathrm{L})$} \\
\hline & & & SCG Extract & SFB & SDS \\
\hline F9 & Benzofuran & & $18 \pm 1$ & - & - \\
\hline F10 & 2-Acetylfuran & Balsamic & $550 \pm 6^{B}$ & $2350 \pm 21^{\mathrm{A}}$ & $152 \pm 3^{C}$ \\
\hline F11 & 5-Methyl-2-propenyl furan & & $105 \pm 2^{\mathrm{A}}$ & $4 \pm 1^{C}$ & $27 \pm 1^{\mathrm{B}}$ \\
\hline F12 & Methyl Furfuryl Disulphide & Smoke & $66 \pm 3$ & - & - \\
\hline F13 & 2-(2-Furfuryl)furan & & $768 \pm 14^{\mathrm{A}}$ & $70 \pm 3^{C}$ & $309 \pm 6^{B}$ \\
\hline F14 & 5-Methyl-2-propiony furan & & $252 \pm 5$ & - & - \\
\hline F15 & Difurfuryl ether & & $1015 \pm 10^{\mathrm{A}}$ & $608 \pm 9^{B}$ & - \\
\hline F16 & $\begin{array}{l}\text { 2-Furfuryl-5-methyl furan } \\
\text { Terpenes }\end{array}$ & & $532 \pm 11^{\mathrm{A}}$ & $64 \pm 1^{C}$ & $82 \pm 1^{\mathrm{B}}$ \\
\hline $\mathrm{T} 1$ & $\beta$-Myrcene & Balsamic, must, spice & $13 \pm 1^{\mathrm{B}}$ & - & $99 \pm 3^{A}$ \\
\hline $\mathrm{T} 2$ & DL-Limonene & & $80 \pm 2^{B}$ & $48 \pm 3^{B}$ & $396 \pm 9^{A}$ \\
\hline $\mathrm{T} 3$ & Styrene & Balsamic, gasoline & $538 \pm 11^{\text {B }}$ & - & $1030 \pm 10^{\mathrm{A}}$ \\
\hline $\mathrm{T} 4$ & $\begin{array}{l}\text { cis-Linaloloxide (2-methyl-2-vinyl-5-(alpha } \\
\text { hydroxyisopropyl) tetrahydrofuran) }\end{array}$ & Flower, wood & $308 \pm 3^{\mathrm{A}}$ & $213 \pm 6^{\mathrm{B}}$ & - \\
\hline $\mathrm{T} 5$ & Camphor & Camphor & $199 \pm 4$ & - & - \\
\hline $\mathrm{T} 6$ & Linalool & & $273 \pm 3^{A}$ & $254 \pm 6^{\mathrm{B}}$ & - \\
\hline $\mathrm{T} 7$ & $\begin{array}{l}\beta \text {-Damascenone } \\
\text { Pyrroles }\end{array}$ & Apple. rose, honey & $173 \pm 2^{\mathrm{A}}$ & $19 \pm 1^{\mathrm{B}}$ & - \\
\hline Pyr1 & 3-Methylpyrrole & & $53 \pm 4^{\mathrm{B}}$ & $368 \pm 7^{\mathrm{A}}$ & - \\
\hline Pyr2 & $\mathrm{N}$-methyl-2-acetyl pyrrole & & $571 \pm 14^{\mathrm{B}}$ & $808 \pm 9^{\mathrm{A}}$ & - \\
\hline Pyr3 & $\begin{array}{l}\text { 1-Furfurylpyrrole } \\
\text { Lactones }\end{array}$ & & $893 \pm 15$ & - & - \\
\hline $\mathrm{L} 1$ & $\begin{array}{l}\gamma \text {-Butyrolactone } \\
\text { Others }\end{array}$ & Caramel, sweet & $83 \pm 2^{\mathrm{B}}$ & $167 \pm 5^{\mathrm{A}}$ & - \\
\hline $\mathrm{O} 1$ & 3,4-Diethylthiophene & & - & - & $19 \pm 2$ \\
\hline $\mathrm{O} 2$ & 4-Methylthiazole & Roasted meat & $63 \pm 4$ & - & - \\
\hline
\end{tabular}

Values shown represent the averages of triplicate samples (data are mean \pm SD). Values with different superscript letters in the same row are significantly different $(p<0.05)$. -: not detected. Spent coffee grounds: namely SCG. SCG fermented beverages: namely SFB. SCG distilled spirits: namely SDS. * http:/ / www.flavornet.org/flavornet.html (accessed on 22 October 2021).

a

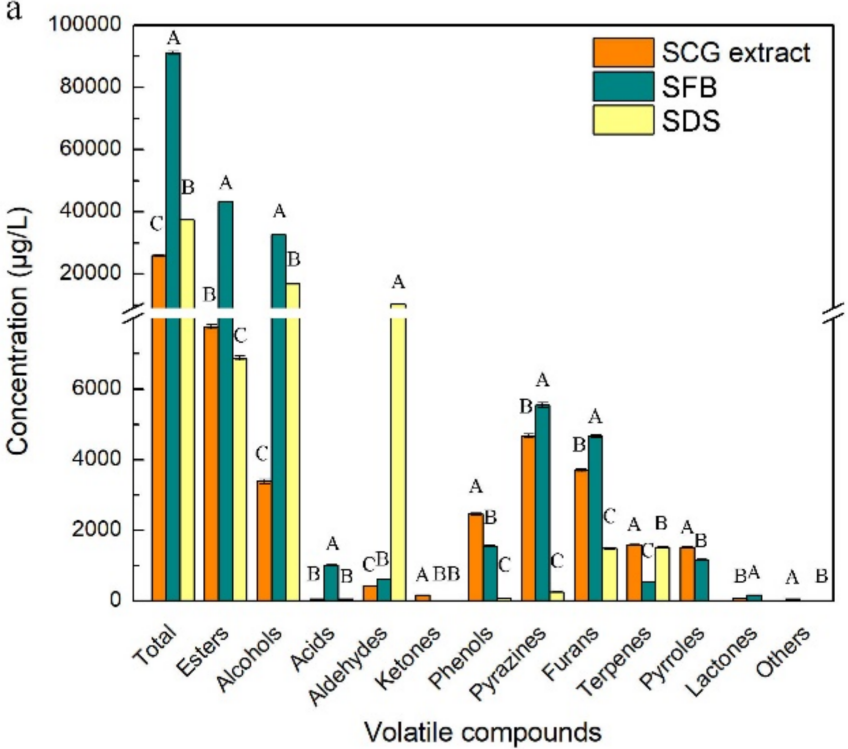

$\mathrm{b}$

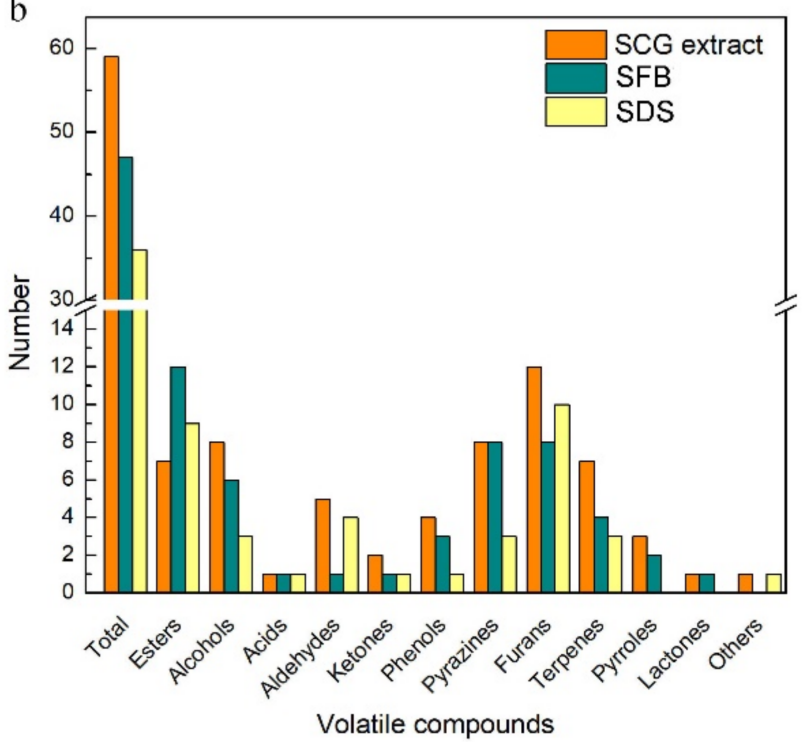

Figure 4. Variation in (a) concentration and (b) number of volatile compounds in samples. SFB: SCG fermented beverages. SDS: SCG distilled spirits. Values with different capital letters upon the columns of the same item are significantly different $(p<0.05)$.

Compared with SCG extract, 20 volatile compounds including 1 ester, 2 alcohols, 5 aldehydes, 1 ketone, 1 phenol, 5 furans, 3 terpenes, 1 pyrrole, and 1 thiazole lost in SFB, but those for SDS were 36 volatile compounds including 1 ester, 5 alcohols, 4 aldehydes, 2 ketones, 3 phenols, 6 pyrazines, 6 furans, 4 terpenes, 3 pyrroles, 1 lactone, and 1 thiazole. 
Simultaneously, 8 volatile compounds, including 6 esters, 1 aldehyde, and 1 furan were added in SFB, compared with SCG extract, and those for SDS were 13 volatile compounds including 3 esters, 3 aldehydes, 1 ketone, 1 pyrazine, 4 furans, and 1 thiophene. These results reflected that the better aroma sense of SDS was not due to the higher retention of original aroma, but might be due to the few fermentation aromas. Two types of aromas balanced and the original aroma was uncovered. Aldehydes, furans, and terpenes were the first three decreasing groups in SFB in terms of the number of compounds, accounting from $1.7 \%$ to $0.7 \%, 14.3 \%$ to $5.1 \%$, and $6.1 \%$ to $0.6 \%$, respectively. Aldehydes produce in the early stage of alcohol fermentation and are subsequently reduced to alcohols and $\mathrm{CO}_{2}$. Furans and terpenes can be formed via carbohydrate degradation during alcohol fermentation $[48,49]$. The loss of several furans and terpenes might convert to other types of volatile compositions, such as increased pyrroles converted from furans. The absence of several aldehydes, furans, and terpenes might affect the typicality of coffee aroma of SFB. However, the stimulating aroma might be decreased in SFB, generating a harmonious overall aroma.

Esters were the most noteworthy group in terms of the variation of number and content of volatile compounds. The number and proportion of esters in SFB increased from 7 to 12 and from $30.0 \%$ to $47.4 \%$, respectively. The increased alcohol and acid provided sufficient precursors for the synthesis of esters in SFB. The increase of esters enhanced fruity aroma of SFB, which was consistent with the results of physicochemical and sensory evaluation (Table 1). The rich fruity flavor could alleviate the prominent sour and astringent tastes of SFB to a certain extent.

The odor activity values (OAVs) were used to further investigate the contribution of each compound to the flavor of SFB and SDS (Table 3). The OAVs of 28 volatile compounds were above 1 in this test. Amongst them, 17, 13, and 8 compounds were shown in SCG extract, SFB, and SDS, respectively. The largest number of esters possessing OAV $>1$ was observed in SFB, thus contributing the rich fruity odor to SFB. As with SCG extract, several aldehydes of SDS exhibited OAV $>1$. However, strong fatty, ether, and sweet odors were negative to wine flavor. Compared with SCG extract, the outstanding alcohols-, ketones-, and pyrroles-induced odors might disappear in SFB and SDS, but phenols- and terpenes-induced odors may remain with OAVs of 4-ethyl-2-methoxyphenol, 4-allyl-2methoxyphenol, styrene, linalool, and $\beta$-damascenone $>1$. As one of the major groups of the typical flavors of coffee, furans might contribute the most in SFB with the OAV of furfuryl ethyl ether $>1$, and furans-induced odors might balance with the fruity odor induced by esters. The odor threshold values of many furan compounds did not be retrieved from literature. Therefore, the contribution of furans to SDS could not be ignored.

Table 3. OAVs (>1) for the main volatile compounds in SCG extract, SFB, and SDS.

\begin{tabular}{|c|c|c|c|c|c|}
\hline Code & Compounds & Odor Description * & SCG Extract & SFB & SDS \\
\hline \multicolumn{6}{|c|}{ Esters } \\
\hline E1 & Ethyl acetate & Pineapple & 1421.0 & 4.9 & 0.8 \\
\hline E2 & Ethyl propionate & Fruit & 255.6 & 20.8 & / \\
\hline E3 & Ethyl 2-methylpropanoate & Sweet, rubber & - & - & 7.3 \\
\hline E5 & Ethyl butyrate & Apple & 560.0 & - & - \\
\hline E7 & Ethyl 3-methylbutanoate & Fruit & - & 1.3 & - \\
\hline E8 & Isoamyl acetate & Banana & 0.2 & 44.9 & 6.2 \\
\hline E9 & Ethyl hexanoate & Apple peel, fruit & 12.6 & 46.5 & 0 \\
\hline E10 & Ethyl octanoate & Fruit, fat & 8.9 & 35.9 & 6.0 \\
\hline E13 & Ethyl decanoate & Grape & 12.4 & 1.3 & 0.2 \\
\hline E15 & $\begin{array}{c}\text { Phenethyl acetate } \\
\text { Alcohols }\end{array}$ & Rose, honey, tobacco & - & 0.6 & - \\
\hline A1 & 2-Methyl-1-butanol & Wine, onion & 29.7 & 0.2 & 0.1 \\
\hline A2 & 3-Methyl-1-butanol & Whiskey, malt, burnt & / & 0.4 & 0.7 \\
\hline A4 & $\begin{array}{l}\text { 2-Heptanol } \\
\text { Aldehydes }\end{array}$ & Mushroom & 0.5 & - & - \\
\hline Al1 & Ethanal & Pungent, ether & - & 0.5 & 1629.1 \\
\hline
\end{tabular}


Table 3. Cont.

\begin{tabular}{|c|c|c|c|c|c|}
\hline Code & Compounds & Odor Description * & SCG Extract & SFB & SDS \\
\hline $\mathrm{Al} 3$ & Acetaldehyde diethyl acetal & & - & - & 6.4 \\
\hline Al4 & (Z)-4-heptenal & Biscuit, cream & 12.4 & - & - \\
\hline $\mathrm{A} 15$ & Octanal & Fat, soap, lemon, green & 1.5 & - & - \\
\hline Al6 & Nonanal & Fat, citrus, green & 15.9 & - & - \\
\hline Al8 & $\begin{array}{l}\text { Phenylethanal } \\
\text { Ketones }\end{array}$ & Hawthorne, honey, sweet & 55.0 & - & 1.0 \\
\hline K1 & $\begin{array}{l}\text { 2-Methylpentan-3-one } \\
\text { Phenols }\end{array}$ & Mint & 5.8 & / & - \\
\hline $\mathrm{P} 2$ & 4-Ethyl-2-methoxyphenol & Spice, clove & 26.4 & 37.3 & 1.8 \\
\hline P4 & $\begin{array}{l}\text { 4-Allyl-2-methoxyphenol } \\
\text { Furans }\end{array}$ & Clove, honey & 1464.7 & 39.8 & - \\
\hline F2 & $\begin{array}{c}\text { Furfuryl ethyl ether } \\
\text { Terpenes }\end{array}$ & & - & 138.0 & 0.9 \\
\hline $\mathrm{T} 3$ & Styrene & Balsamic, gasoline & / & - & 4.1 \\
\hline T6 & Linalool & & 2.7 & 10.2 & - \\
\hline $\mathrm{T} 7$ & $\begin{array}{c}\beta \text {-Damascenone } \\
\text { Pyrroles }\end{array}$ & Apple. rose, honey & / & 380.0 & - \\
\hline Pyr3 & $\begin{array}{l}\text { 1-Furfurylpyrrole } \\
\text { Lactones }\end{array}$ & & 8.9 & - & - \\
\hline L1 & $\gamma$-Butyrolactone & Caramel, sweet & 2.4 & 4.8 & - \\
\hline
\end{tabular}

-: not detected./not calculated due to unreferenced odor threshold values. ${ }^{*}$ http://www.flavornet.org/flavornet.html (accessed on 22 October 2021). OAVs were calculated by the ratio of the concentration of a compound to its odor threshold value. To calculate the OAVs of compounds in SCG extract, SFB, and SDS, odor threshold values in water, low content of alcohol $(<15 \%)$, and high content of alcohol $(>40 \%)$ were referred from literature, respectively.

\section{Conclusions}

The supplement of $0.20 \%\left(\mathrm{NH}_{4}\right)_{2} \mathrm{HPO}_{4}$ was effective for improving growth and alcohol fermentation of S. cerevisiae D254 in SCG extract. SFB and SDS produced at the optimized fermentation conditions (SCG-liquid ratio 1:4; $24 \%$ sucrose; $\mathrm{pH} 4.3 ; 6 \%$ activated S. cerevisiae strain D254; $23^{\circ} \mathrm{C}$ for 8 days) had appropriate physicochemical properties $(12.5 \%$ and $50.5 \%$ ethanol, respectively; $9.07 \mathrm{~g} / \mathrm{L}$ and $0.37 \mathrm{~g} / \mathrm{L}$ total acidity, respectively) and different sensory characteristics, including aroma and taste senses. Fermentation aromas, especially esters, produced in $\mathrm{SFB}$, increased the complexity of aroma and lowered the irritating aromas, such as nitrogen oxides-induced ones. The combination of original and fermentation aromatic components could balance the outstanding sourness, astringency, and saltiness of SFB. Fermentation aroma was partially lost (e.g., the total contents of esters decreased by $84 \%$, compared with SFB) and the sourness, bitterness, astringency, and saltiness tastes were relieved in distillation according to the electronic tongue system, leading to the relatively more prominent aroma typicality of coffee and a soft taste.

Supplementary Materials: The following are available online at https:/ /www.mdpi.com/article/10 .3390 / fermentation7040254/s1, Figure S1: The brewing process of SCG beverages, Figure S2: Effects of types and concentrations of nitrogen source on a biomass yield of D254, b residual sugar, and c ethanol content in SCG substrate, Figure S3: Effects of a the ratio of SCG $\mathbf{b}$ the inoculation amount of $S$. cerevisiae $\mathrm{D} 254 \mathrm{c}$ the initial content of sucrose $\mathbf{d} \mathrm{pH}$ e fermentation temperature on the physicochemical and sensory properties of SFB, Table S1: Chemical sensors used in electronic nose corresponding to different types of volatile substances, Table S2: Standard solution for electronic tongue analysis, Table S3: Sensory scoring rules for the SCG fermented beverages, Table S4: Performance of different yeast strains in SCG extract. Table S5: Chemical parameters of unfermented SCG extract.

Author Contributions: Conceptualization, C.L. and S.L.; Methodology, Z.L.; Investigation, Z.L.; Resources, C.L. and S.L.; Data Curation, X.Y.; Writing-Original Draft Preparation, L.W., X.Y. and X.L.; Writing-Review \& Editing, X.L. and X.H.; Supervision, C.L. All authors have read and agreed to the published version of the manuscript. 
Funding: This research was funded by [the Hainan Provincial Natural Science Foundation of China] grant number [2019RC083], [the National Natural Science Foundation of China] grant number [31760456], [the Education Department of Hainan Province] grant number [Hnky2019-7], and [the Scientific Research Foundation of Hainan University] grant number [KYQD1660]. The APC was funded by [the National Natural Science Foundation of China].

Institutional Review Board Statement: Not applicable.

Informed Consent Statement: Not applicable.

Data Availability Statement: The original contributions presented in the study are included in the article/Supplementary Material, further inquiries can be directed to the corresponding author.

Acknowledgments: This research was funded by the Hainan Provincial Natural Science Foundation of China (grant number 2019RC083), the National Natural Science Foundation of China, grant number 31760456, the Education Department of Hainan Province, grant number Hnky2019-7, and the Scientific Research Foundation of Hainan University, grant number KYQD1660.

Conflicts of Interest: The authors declare no conflict of interest.

\section{References}

1. Açıkalın, B.; Sanlier, N. Coffee and its effects on the immune system. Trends Food Sci. Technol. 2021, 114, 625-632. [CrossRef]

2. Ruta, L.L.; Farcasanu, I.C. Coffee and yeasts: From flavor to biotechnology. Fermentation 2021, 7, 9. [CrossRef]

3. Campos-Vega, R.; Loarca-Piña, G.; Vergara-Castañeda, H.A.; Oomah, B.D. Spent coffee grounds: A review on current research and future prospects. Trends Food Sci. Technol. 2015, 45, 24-36. [CrossRef]

4. Mussatto, S.J.; Machado, E.M.S.; Martins, S.; Teixeira, J.A. Production, composition and application of coffee and its industrial residues. Food Bioprocess Technol. 2011, 4, 661-672. [CrossRef]

5. Silva, M.; Nebra, S.A.; Machado Silva, M.J.; Sanchez, C.G. The use of biomass residues in the Brazilian soluble coffee industry. Biomass Bioenerg. 1998, 14, 457-467. [CrossRef]

6. da Silveira, J.S.; Durand, N.; Lacour, S.; Belleville, M.P.; Perez, A.; Loiseau, G.; Dornier, M. Solid-state fermentation as a sustainable method for coffee pulp treatment and production of an extract rich in chlorogenic acids. Food Bioprod. Process. 2019, 115, 175-184. [CrossRef]

7. Simões, G.; Demétrio, G.B.; de Paula, G.F.; Ladeira, D.C.; Matsumoto, L.S. Influence of spent coffee grounds on soil microbiological attributes and maize crop. Res. Soc. Dev. 2020, 9, e818986400. [CrossRef]

8. Araújo, M.N.; Azevedo, A.Q.P.L.; Hamerski, F.; Voll, F.A.P.; Corazza, M.L. Enhanced extraction of spent coffee grounds oil using high-pressure $\mathrm{CO}_{2}$ plus ethanol solvents. Ind. Crop Prod. 2019, 141, 111723. [CrossRef]

9. Martinez-Saez, N.; García, A.T.; Pérez, I.D.; Rebollo-Hernanz, M.; Mesías, M.; Morales, F.J.; Martín-Cabrejas, M.A.; del Castillo, M.D. Use of spent coffee grounds as food ingredient in bakery products. Food Chem. 2017, 216, 114-122. [CrossRef]

10. Panusa, A.; Zuorro, A.; Lavecchia, R.; Marrosu, G.; Petrucci, R. Recovery of natural antioxidants from spent coffee grounds. J. Agric. Food Chem. 2013, 61, 4162-4168. [CrossRef]

11. Sampaio, A.; Dragone, G.; Vilanova, M.; Oliveira, J.M.; Teixeira, J.A.; Mussatto, S.I. Production, chemical characterization, and sensory profile of a novel spirit elaborated from spent coffee ground. LWT-Food. Sci. Technol. 2013, 54, 557-563. [CrossRef]

12. Gouvea, B.M.; Torres, C.; Franca, A.S.; Oliveira, L.S.; Oliveira, E.S. Feasibility of ethanol production from coffee husks. Biotechnol. Lett. 2009, 31, 1315-1319. [CrossRef]

13. Hughes, S.R.; López-Núñez, J.C.; Jones, M.A.; Moser, B.R.; Cox, E.J.; Lindquist, M.; Galindo-Leva, L.A.; Riaño-Herrera, N.M.; Rodriguez-Valencia, N.; Gast, F.; et al. Sustainable conversion of coffee and other crop wastes to biofuels and bioproducts using coupled biochemical and thermochemical processes in a multi-stage biorefinery concept. Appl. Microbiol. Biotechnol. 2014, 98, 8413-8431. [CrossRef]

14. Machado, E.; Mussatto, S.; Teixeira, J.; Vilanova, M.; Oliveira, J. Increasing the sustainability of the coffee agro-industry: Spent coffee grounds as a source of new beverages. Beverages 2018, 4, 105. [CrossRef]

15. Garcia, C.V.; Kim, Y.T. Spent coffee grounds and coffee silverskin as potential materials for packaging: A review. J. Polym. Environ. 2021, 29, 2372-2384. [CrossRef]

16. Liu, Y.J.; Yuan, W.Q.; Lu, Y.Y.; Liu, S.Q. Biotransformation of spent coffee grounds by fermentation with monocultures of Saccharomyces cerevisiae and Lachancea thermotolerans aided by yeast extracts. LWT-Food Sci. Technol. 2021, 138, 110751. [CrossRef]

17. Liu, Y.J.; Seah, R.H.; Abdul Rahaman, M.S.; Lu, Y.Y.; Liu, S.Q. Concurrent inoculations of Oenococcus oeni and Lachancea thermotolerans: Impacts on non-volatile and volatile components of spent coffee grounds hydrolysates. LWT-Food Sci. Technol. 2021, 148, 111795. [CrossRef]

18. Liu, Y.J.; Lu, Y.Y.; Liu, S.Q. The potential of spent coffee grounds hydrolysates fermented with Torulaspora delbrueckii and Pichia kluyveri for developing an alcoholic beverage: The yeasts growth and chemical compounds modulation by yeast extracts. Curr. Res. Food Sci. 2021, 4, 489-498. [CrossRef] 
19. Buratti, S.; Ballabio, D.; Benedetti, S.; Cosio, M.S. Prediction of Italian red wine sensorial descriptors from electronic nose, electronic tongue and spectrophotometric measurements by means of Genetic Algorithm regression models. Food Chem. 2007, 100, 211-218. [CrossRef]

20. Jo, Y.; Gu, S.Y.; Chung, N.; Gao, Y.; Kim, H.J.; Jeong, M.H.; Jeong, Y.J.; Kwon, J.H. Comparative analysis of sensory profiles of commercial cider vinegars from Korea, China, Japan, and US by SPME/GC-MS, E-nose, and E-tongue October Korean. J. Food Sci. Technol. 2016, 48, 430-436.

21. Zhao, G.Z.; Feng, Y.X.; Hadiatullah, H.; Zheng, F.P.; Yao, Y.P. Chemical characteristics of three kinds of Japanese soy sauce based on electronic senses and GC-MS analyses. Front. Microbiol. 2021, 11, 3222. [CrossRef]

22. Sharma, S.; Mahant, K.; Sharma, S.; Thakur, A.D. Effect of nitrogen source and citric acid addition on wine preparation from Japanese persimmon. J. I. Brewing 2017, 123, 144-150. [CrossRef]

23. Hlaing, M.T.; Joshy, C.G. Optimization of fermentation process for the preparation of coffee wine by response surface methodology. Dagon Univ. Commem. 25th Anniv. Silver Jubil. Res. J. 2019, 9, 2.

24. Yu, L.; Du, J.H.; Wang, X.J.; Yin, Q. Study on resistance of Saccharomyces cerevisiae sp. to citric acid. Sci. Technol. Food Ind. 2008, 29, 148-151.

25. Wang, B.S.; Li, L.B.; Wu, Z.W.; Zhang, L.; Chen, F.; Chen, L.; Zhang, M.X. Inhibiting effects of high concentration of citric acid on the growth of Saccharomyces cerevisiae. China Brew. 2018, 37, 56-60.

26. Li, Z.T.; Li, C.F.; Jia, Y.Y.; Wang, Q.K.; Lu, Y.S.; Wang, M.Y.; Huang, Q.; Liu, S.X. Screening of yeast for coffee-grounds wine fermentation and research on nitrogen source for nutritional condition optimization. China Brew. 2016, 35, 61-64.

27. Gutiérrez, A.; Chiva, R.; Sancho, M.; Beltran, G.; Arroyo-López, F.N.; Guillamon, J.M. Nitrogen requirements of commercial wine yeast strains during fermentation of a synthetic grape must. Food Microbiol. 2012, 31, 25-32. [CrossRef]

28. Beltran, G.; Novo, M.; Rozès, N.; Mas, A.; Guillamón, J.M. Nitrogen catabolite repression in Saccharomyces cerevisiae during wine fermentations. FEMS Yeast Res. 2004, 4, 625-632. [CrossRef]

29. Lucero, P.; Moreno, E.; Lagunas, R. Catabolite inactivation of the sugar transporters in Saccharomyces cerevisiae is inhibited by the presence of a nitrogen source. FEMS Yeast Res. 2002, 1, 307-314.

30. Hernandez-Orte, P.; Ibarz, M.J.; Cacho, J.; Ferreira, V. Effect of the addition of ammonium and amino acids to musts of Airen variety on aromatic composition and sensory properties of the obtained wine. Food Chem. 2005, 89, 163-174. [CrossRef]

31. Santos, J.; Leitão-Correia, F.; Sousa, M.J.; Leão, C. Ammonium is a key determinant on the dietary restriction of yeast chronological aging in culture medium. Oncotarget 2015, 6, 6511-6523. [CrossRef] [PubMed]

32. Forkert, P.G. Mechanisms of lung tumorigenesis by ethyl carbamate and vinyl carbamate. Drug Metab. Rev. 2010, 42, 355-378. [CrossRef] [PubMed]

33. Silla, S.M.H. Biogenic amines: Their importance in foods. Int. J. Food Microbiol. 1996, 29, $213-231$.

34. Hernanz, D.; Gallo, V.; Recamales, A.F.; Melendez-Martinez, A.J.; Gonzalez-Miret, M.L.; Heredia, F.J. Effect of storage on the phenolic content, volatile composition and colour of white wines from the varieties zalema and colombard. Food Chem. 2009, 113, 530-537. [CrossRef]

35. Bressani, A.P.P.; Martinez, S.J.; Sarmento, A.B.I.; Borém, F.M.; Schwan, R.F. Organic acids produced during fermentation and sensory perception in specialty coffee using yeast starter culture. Food Res. Int. 2020, 128, 108773. [CrossRef]

36. De Bruyn, F.; Zhang, S.J.; Pothakos, V.; Torres, J.; Lambot, C.; Moroni, A.V.; Callanan, M.; Sybesma, W.; Weckx, S.; De Vuyst, L. Exploring the impacts of postharvest processing on the microbiota and metabolite profiles during green coffee bean production. Appl. Environ. Microbiol. 2016, 83, e02398-16. [CrossRef]

37. Evangelista, S.R.; da Cruz Pedrozo Miguel, M.G.; de Souza Cordeiro, C.; Silva, C.F.; Pinheiro, A.C.M.; Schwan, R.F. Inoculation of starter cultures in a semi-dry coffee (Coffea arabica) fermentation process. Food Microbiol. 2014, 44, 87-95. [CrossRef]

38. Dzialo, M.C.; Park, R.; Steensels, J.; Lievens, B.; Verstrepen, K.J. Physiology, ecology and industrial applications of aroma formation in yeast. FEMS Microbiol. Rev. 2017, 41, S95-S128. [CrossRef]

39. Ma, P.X.; Zhang, B.C.; Zhang, Y. Research on the difference between Chinese quality brandy and French quality brandy. Liquor-Mak. Sci. Technol. 2011, 1, 47-51.

40. Sunarharum, W.B.; Williams, D.J.; Smyth, H.E. Complexity of coffee flavor: A compositional and sensory perspective. Food Res. Int. 2014, 62, 315-325. [CrossRef]

41. Lee, S.J.; Kim, M.K.; Lee, K.G. Effect of reversed coffee grinding and roasting process on physicochemical properties including volatile compound profiles. Innov. Food Sci. Emerg. Technol. 2017, 44, 97-102. [CrossRef]

42. Ribeiro, L.S.; Miguel, M.G.; Evangelista, S.R.; Machado Martins, P.M.; van Mullem, J.; Belizario, M.H.; Schwan, R.F. Behavior of yeast inoculated during semi-dry coffee fermentation and the effect on chemical and sensorial properties of the final beverage. Food Res. Int. 2017, 92, 26-32. [CrossRef]

43. Czerny, M.; Christlbauer, M.; Christlbauer, M.; Fischer, A.; Granvogl, M.; Hammer, M.; Hartl, C.; Hernandez, N.M.; Schieberle, P. Re-investigation on odour thresholds of key food aroma compounds and development of an aroma language based on odour qualities of defined aqueous odorant solutions. Eur. Food Res. Technol. 2008, 228, 265-273. [CrossRef]

44. Lin, X.; Wang, Q.K.; Wu, W.Y.; Zhang, Y.X.; Liu, S.X.; Li, C.F. Evaluation of different Saccharomyces cerevisiae strains on the profile of volatile compounds in pineapple wine. J. Food Sci. Technol. 2018, 55, 4119-4130. [CrossRef]

45. Nyanga, L.K.; Nout, M.J.; Smid, E.J.; Boekhout, T.; Zwietering, M.H. Fermentation characteristics of yeasts isolated from traditionally fermented masau (Ziziphus mauritiana) fruits. Int. J. Food Microbiol. 2013, 166, 426-432. [CrossRef] 
46. Lin, X.; Wu, L.F.; Wang, X.; Yao, L.L.; Wang, L. Ultrasonic-assisted extraction for flavonoid compounds content and antioxidant activities of India Moringa oleifera L. leaves: Simultaneous optimization, HPLC characterization and comparison with other methods. J. Appl. Res. Med. Aromat. Plants 2021, 20, 100284.

47. Wu, L.F.; Li, L.; Chen, S.J.; Wang, L.; Lin, X. Deep eutectic solvent-based ultrasonic-assisted extraction of phenolic compounds from Moringa oleifera L. leaves: Optimization, comparison and antioxidant activity. Sep. Purif. Technol. 2020, $274,117014$. [CrossRef]

48. Lin, X.; Jia, Y.; Li, K.; Hu, X.P.; Li, C.F.; Liu, S.X. Effect of the inoculation strategies of selected Metschnikowia agaves and Saccharomyces cerevisiae on the volatile profile of pineapple wine in mixed fermentation. J. Food Sci. Technol. 2021. [CrossRef]

49. Sun, S.Y.; Jiang, W.G.; Zhao, Y.P. Evaluation of different Saccharomyces cerevisiae strains on the profile of volatile compounds and polyphenols in cherry wines. Food Chem. 2011, 2, 547-555. [CrossRef] 